\title{
Integrating Global Open and Satellite-based Information for Major Disaster Damage Assessment
}

\author{
Suju $\mathrm{Li}^{1}$, Haixia $\mathrm{He}^{1}$, Yan Cui ${ }^{1}$, Ming Liu ${ }^{1}$, Shirish Ravan ${ }^{2}$ \\ 1. National Disaster Reduction Center of China, Ministry of Civil Affairs, Beijing, China \\ 2. United Nations Office of Out Space Affairs, Vienna, Austria \\ lisuju@ndrcc.gov.cn,hehaixia@ndrcc.gov.cn,cuiyan@ndrcc.gov.cn,shirish.ravan@unoosa.org
}

Keywords:global open data; integration; damage assessment; major disasters

\begin{abstract}
Major disasters usually impact large area and cause massive damages to variety physical elements resulting into heavy economic losses. Timely and accurate assessment of disaster damages is critical for better understanding the situation and further supporting the emergency response activities. Geo-information and satellite remote sensing imagery from various sources with multi spatialtemporal scales has been widely used for charting the disaster and assessing the caused damage. With increased global open datasets, earth observation satellites and international cooperation initiatives, more information are available for disaster damages assessment through appropriate integrating, especially for rapid estimation just after the disaster. The main exposure elements impacted by the flood in Myanmar in 2015 has been estimated based on the integration of open dataset GL30 and imageries from 3 Chinese satellites as study case. The challenges and prospects considering the past and current development are discussed.
\end{abstract}

\section{INTRODUCTION}

Major disasters pose global challenges in the world not only because they usually covered large areas and some even cause impacts across the borders of nations, but also because that they usually bring massive damages to variety physical elements resulting into heavy economic losses. For example, the Earthquake in Nepal from April 2015 resulted in 8831 death, over 5 billion US\$ losses and affected not only Nepal but also India and China. Some of them even need international assistance for emergency response and relief. Timely and accurate assessing the caused damages is critical for better understanding the overall impact of disaster and supporting more scientific decision making for rescue, relief and reconstruction implementation.

The disaster affected population, damaged physical assets and infrastructure are usually the most concerned elements at the stage of emergency response, which could be fast estimated through spatial synthesis of the impact extent and exposure elements. Imageries of earth observation satellites have been widely used for disaster extent identification and damage assessment for their remote, wide covering, revisiting and all weather observing advantages ${ }^{[1]}$. Exposure information is the key and basic information for disaster damage assessment. Many countries have developed the database of some exposure elements such as population, settlement and arable land through survey or reporting but lack of spatialized data. The developing of global open datasets narrows the gap in this regard. Some exposure elements could be derived from the available global open geo-datasets, which dramatically facilitate the major disaster damage assessment for those countries lack of referenced exposure geo-information. By collecting, processing and analyzing the disaster related geo-information with multisources, variable formats at different levels and scales through appropriate integration approaches could not only assess the disaster damage efficiently but also could describe the spatial and temporal patterns of the disaster elements and damage status.

With the development of advanced geo-information technologies, especially the earth observation and crowdsourcing, large volume and various types of information are accessible for and have facilitated to estimate the disaster impact and damage. The increased availability of open source data and international cooperation initiatives is helping to share and use geospatial data for disaster damage assessment. A group of tens countries have joined the Open Government Partnership with promotion to open their government data using for various purposes including disaster emergency. Within the framework of International Charter "Space and Major Disasters", more than 20 earth observation satellites with variety of optical or synthetic aperture radar (SAR) sensors could be mobilized and tasked for acquiring earth observation data of the disaster affected area during major disaster emergency stage. At the same time, the geo-information infrastructures such as Infrastructure for Spatial Information in the European Community (INSPIRE) also promotes open access and use for disaster management through structured and standardized data management.

Despite the above efforts, gaps still exist between information required and its availability, especially for damage assessment. When confronting major disaster, it is great a challenge to collect, process and analysis so many data at one time for any one single institution. To access and integrate those multi sourced information for better and faster damage assessment, both technical and non-technical approaches are required and proposed. Some available global geo-information and integrated approaches for damage estimation are outlined and analyzed. Major flood occurred in Myanmar from July to August in 2015 is taken as the case study to discuss the utility of global open and satellite based information and its integration for impact estimation. This paper also presents the challenges and perspectives in 
integrated using multi sourced geo-information for damage assessment by putting past and current developments in this domain.

\section{SOME GLOBAL OPEN DATA AND SATELLITE BASED INFORMATION}

\section{A. Global Open Datasets}

For the purpose of this paper global open source datasets are the datasets that are available globally either free of cost or at low cost. With advent of web based geo-information platforms and promotion of global open source data, enormous geo-datasets are accessible for the purpose of disaster management. Although global open source dataset are available at coarser scale compared to the local scale geodatasets, these are suitable for fast and large scale damage estimation as it comes in standard formats. Global datasets are usually derived through top down integration approaches. At global scale, exposure data are usually based on national open statistical and census data, global databases and remote sensing. Global open exposure datasets development is extremely essential for major disaster damage assessment for global efforts.

Several global open datasets are important exposure information which could be easily used for rapid post disaster impact estimation. The Gridded Population of the World (GPW) series, now in its fourth version (GPWv4), models the distribution of human population. Density consists of estimates of human population density based on counts consistent with national censuses and population registers for the years 2000,2005,2010,2015 and 2020. The Global Urban Footprint is developed by the German Aerosapce Center(DLR ) based on the global datasets of the TerraSAR-X and TanDEM-X mission between 2011 and 2013 at 12 meters resolution is available for scientist since the end of 2014. The GlobaLand30(GL30) datasets ${ }^{[2]}$ is a global open dataset extracted from more than 20,000 Landsat and $\mathrm{HJ}-1$ images at 30 meter resolution ranging from year 2000 to 2010. There are 10 land cover types being included in the datasets, among which artificial surface and cultivated land are two most frequently used as exposure information for fast disaster impact estimation.

\section{B. Accessible Satellite Based Information}

Earth Observations(EO) satellites have served as an important information resource for disaster emergency response. Earth observation satellites with various setting configurations could detect the post disaster situation and the affected elements of building, infrastructure, assets and relief materials. Since the turn of the century, earth observation technology have increasingly been used to help assess impact and support emergency response following major disasters around the world. The availability of scientific and commercial EO satellite systems has increased during the past 15 years. Reprogramming the EO satellite systems and collecting imagery over the disaster site typically takes 1 or 2 days.These satellites are equipped with optical at different electromagnetic spectrum or radar imaging sensors at different frequencies ${ }^{[3]}$. At the same time, since only a few countries own remote sensing satellites resources but all countries facing the challenges of major disasters, more satellite operators and experts endeavored join their efforts for improving emergency mapping efficiency.

There are also several satellite based emergency mapping mechanisms having been successfully operated at different levels for providing imageries and mapping service for major disasters emergency response. International Charter Space and Major Disasters has been activated for emergency mapping service for about 500 major disasters worldwide since 2000 based on more than 20 on-orbit remote sensing satellites. European COPERNICUS Emergency Management Service programme could provide not only rapid mapping with service but also risk and recovery mapping service. United Nationals Space-based Information for Disaster Management and Emergency Response(UN-SPIDER) programme and Operational Satellite Applications Programme(UNOSAT) are two initiatives under United Nations System provide space-based information through mapping and collecting approached respectively ${ }^{[4]}$.

\section{INTEGRATION INFORMATION FOR MAJOR DISASTER DAMAGE ASSESSMENT}

The types of major disasters damage assessment are different along the emergency response process. Three kinds of damage assessment could be classified based on the different post disaster phases, rapid estimation, dynamic assessment and comprehensive assessment. The longer time taken, more types and detailed data could be accessed and used, the outcome will be more accurate. Rapid disaster estimation is usually estimate the possible disaster impact within one hour or even minitues after disaster happens mostly based on experimental approaches and historical data. Disaster comprehensive damage assessment is conducted based on thorough and detailed datasets and multiple approaches including ground survey and sometimes lasted for months, which will give accurate outcome for further recovery and reconstruction planning. From hour to days is the phase of dynamic damage assessment information for supporting the emergency rescue and relief activities. Since both the baseline and post disaster information are in the progress of completing and updating at this stage, dynamic damage assessment is usually implemented based on integration as much available information as possible.

Disaster is a complex, uncertain and dynamic issue. Estimation the damage caused by disasters is also a complicated and nonlinear problem. As a technology of integration, geo-information technology could be one of the prerequisite for the efficient damage estimation. In fact major disaster damage assessment is the most suitable application field for global and local geo-information integration not only because amount of heterogeneous multisourced information is needed but also for the various damage assessment requirements and the diverse available methodologies or models. When used for disaster damage assessment, explicit requirements should be the driven factor and be best handled for geo-information integration, not by integrating all forms of geographic analysis in one package but by providing appropriate linkages and hooks to allow resource components to act in a federation. Global open and satellite based information integration has been proven an 
effective way for efficient disaster damage assessment ${ }^{[5]}$. The integration could be implemented at the level of data, methodology or models, tools and platforms, for each level, both technical and non-technical approaches should be considered for better estimation proceeding. There are some best application practices and modalities been developed and valued for further spreading.

\section{MYANMAR FLOOD AFFECTED ESTIMATION}

\section{A. Flood Disaster and Information Collection}

Myanmar is the largest country of South-East Asia located between 9032 ' N \& 28031' N Latitude and 92010'E \& 101011'E Longitude. It has been administratively divided into 7 Divisions and 7 States. Myanmar is exposed to multiple natural hazards including cyclone, earthquake, floods and fire. It has been periodically hit by floods. According to EM-DAT databased, during 2000 to 2015, there are 30 major natural disasters including 15 flood disasters recorded which has caused 139 thousand people dead.

From July to August in 2015, Myanmar was hit by a major flood disaster because of the influence of heavy monsoon rains and a typhoon. 12 of 14 states and regions of the country were affected by the disaster. A total of 1.6 million people were affected and over 100 people lost their lives. On July 31, the President of Myanmar declared Chin and Rakhine states, and Magway and Sagaing regions as flood disaster zones and welcomed international assistance for the flood response.

To assist Myanmar for flood emergency response, National Disaster Reduction Center of China (NDRCC) tasked $\mathrm{HJ}-1 \mathrm{~A} / \mathrm{B}$ and $\mathrm{SJ}-9 \mathrm{~A}$ satellites covered the whole country for flood extent estimation. HJ-A/B were two small satellites used for disaster and environment monitoring lunched in 2008 by China. A optical sensor with $30 \mathrm{~m}$ spatial resolution and $720 \mathrm{~km}$ swath was widely used for water body detection. Both the archived and post flooded imageries HJ1A/B were acquired. SJ-9A satellite was a Chinese technology experimental satellite launched in 2012. At the same time, GL30 land cover data, open baseline geoinformation from Myanmar Information Management Unit (MIMU) and disaster situation information from relief web were all used for the estimation. During the flood emergency stage, totally 73 scenes of satellites images have been accessed with 25 scenes archived images and 48 scenes of new tasked.

\section{B. Flooded Extent and Impact Estimation}

Flood affected elements were estimated by three steps. Firstly, the possible extent of flood was extracted through the approaches of comparing analysis and change detection of the pre and post-flood images by scene. Secondly flooded extent of the whole country was derived through geocombining all the above extracted flooded extents into one integrated layer. Finally, the GL30 and MIMU data were used as the exposure elements to estimate the impact of floods on administrative unit, cropland and human settlements by integrated with the above flooded extent information.

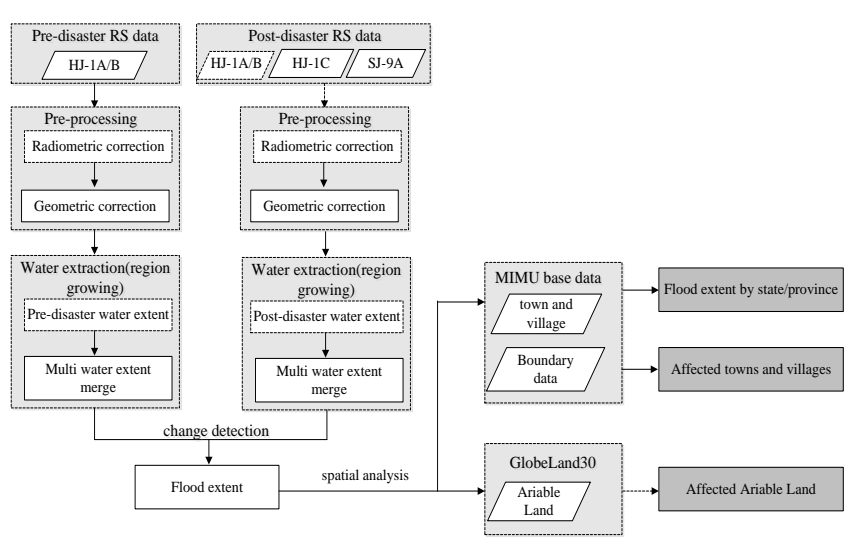

Fig. 1. Information Integration Framework for Damage Assessment

\section{Results and discussion}

The flooded areas were mostly located in valley region along rivers and the arable land and high density residential areas were the elements damaged mostly by flood. Within the $12,000 \mathrm{~km}^{2}$ remote sensing derived flooding area, 1747 villages distributed in 108 townships were distributed inside. More than $9000 \mathrm{~km}^{2}$ flooded area were arable land. Ayeyarwady was the largest flooded area covered with most villages and arable land affected, followed by Bago, Sagaing and Magway. Chin was most slightly affected.

The national covered reference satellite imagery, flooded extent map, maps of flooded residential areas along some big river and assessment report had been provided within 7 days to Myanmar for emergency response reference. The case shew that with the collaboration of satellite observing and available open dataset, it was possible and efficiency for estimating the impact and damage from the third part agency in other countries. Because the lack of situ disaster information, the outcome had not been evaluated. Collaborative validation by both parts should be important for better assessment.

TABLE I. FLOODED ELEMENTS ESTIMATION

\begin{tabular}{|l|c|c|c|c|}
\hline \multirow{2}{*}{ State or region } & \multicolumn{5}{|c|}{ Flooded Elements } \\
\cline { 2 - 5 } & Area $\left(\mathbf{k m}^{2}\right)$ & $\begin{array}{l}\text { Township } \\
\text { number }\end{array}$ & $\begin{array}{l}\text { Villages } \\
\text { number }\end{array}$ & Arable land $\left.\mathbf{( k m}^{2}\right)$ \\
\hline Ayeyarwady & 3980.84 & 14 & 488 & 3120.9 \\
\hline Bago & 1861.44 & 18 & 485 & 1297.4 \\
\hline Chin & 2.56 & 3 & 0 & 0.8 \\
\hline Kachin & 775.25 & 3 & 59 & 606.3 \\
\hline Kayin & 679.93 & 3 & 79 & 483.2 \\
\hline Magway & 1017.51 & 18 & 201 & 561.5 \\
\hline Mandalay & 676.85 & 14 & 35 & 398.1 \\
\hline Mon & 22.08 & 4 & 2 & 21.5 \\
\hline Naypyitaw & 34.62 & 2 & 1 & 14.4 \\
\hline Rakhine & 207.24 & 2 & 9 & 61.5 \\
\hline
\end{tabular}




\begin{tabular}{|l|c|c|c|c|}
\hline Sagaing & 2124.31 & 16 & 304 & 1752.3 \\
\hline Shan & 325.16 & 8 & 38 & 179.6 \\
\hline Yangon & 627.08 & 3 & 46 & 519.6 \\
\hline Total & 12334.9 & 108 & 1747 & 9017.2 \\
\hline
\end{tabular}

volume and verity categories disparate among different agencies, which is difficult for access all those data within short time. Second, although open data policies are promoted by several initiatives, however, but most geo-information under 10 meter resolution which is practical useful for affected elements estimation is strictly limited for sharing or open using. High resolution remote sensing imageries are also very limited using for emergency. Third is that, since the geo-information are usually with multi types and formats

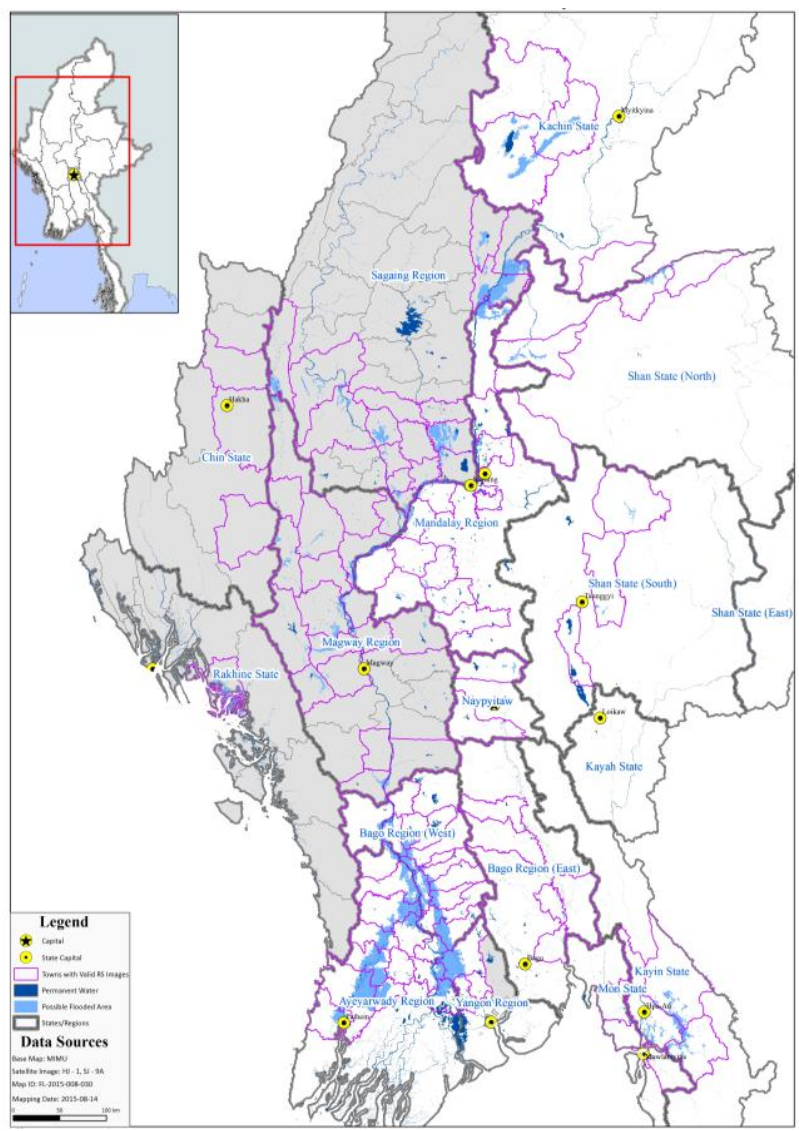

Fig.2 Flooded Area Extracted from Satellite Images

\section{CONCLUSION AND DISCUSSION}

Major natural disasters occurred globally and could caused massive damage and economic loss. Integrating the global open geo information and remote sensing imageries could be effectively used for disaster damage assessment, especially for fast affected extent estimation. At the same time, more geo-information resources will be produced and available for major disaster damage assessment utilization. Increasing open geo-information and remote sensing satellites resources along with the development of geoinformation technology have been dramatically facilitated the implementation in the field of disaster damage assessment. However, with the increasing concerns for supporting geo-information from disaster management community, there are big gaps still existing between the information of the providing and the requiring on its accuracy, timely and readability. To fulfil the gaps, some challenges are facing for both the communities of geoinformation and damage assessment. First is that the data requested for major damage assessment are usually with big because of the lack of uniformed standards and professional processing capacity for most developing countries, it usually takes long time and plenty of energy for the data preparation for further analysis where the datasets are usually not well organised. Additionally, every methodology has its advantages and limitations, how to use them integrated for better outcome synergy is a big challenge as well. Furtherly, the new advances in the field of geo-information, such as crowdsourcing technology are changing the way information being collected and integrated from multiple sources and offered to the end user, but validation and further analysis of those information are need to be explored for better using.

\section{Acknowledgements}

This work was supported by the National Natural Science Foundation of China under Grant "Study on Using Crowdsource Mapping Technology for Major Natural Disaster Response" [41301591]

\section{References}

[1] H. D. Guo, "Understanding global natural disasters and the role of earth observation," International Journal of Digital Earth,vol.3,issue3, pp. 221-230, 2010.

[2] J. Chen, J. Chen, A. Liao, X. Cao, L. Chen, X. Chen, C. He, G. Han, S. Peng, M. Lu, W. Zhang, X. Tong, J. Mills, "Global land cover mapping at $30 \mathrm{~m}$ resolution: A POK-based operational approach," ISPRS Journal of Photogrammetry and Remote Sensing, vol.103, pp.727,2015 .

[3] S.Voigt, F.Giulio-Tonolo, J.Lyons, J.Kučera, B.Jones, T.Schneiderhan, G.Platzeck, K.Kaku, M.K.Hazarika, L.Czaran, S.J.Li, W.Pedersen, G. K. James, C. Proy, D. M. Muthike, J. Bequignon, D.G.Sapir, "Global trends in satellite-based emergency mapping," Science, vol. 353, issue 6296, pp. 247-252,2016.

[4] H. Miyazaki, M. Nagai, R. Shibasaki "Reviews of Geospatial Information Technology and Collaborative Data Delivery for Disaster Risk Management," ISPRS International Journal of Geo-Information, vol 4, pp. 1936-1964, 2015

[5] A. B. Sambah, F. Miura1, "Integration of Spatial Analysis for Tsunami Inundation and Impact Assessment," Journal of Geographic Information System, vol.6,pp 11-22, 2014. 